\title{
Darwin: Origin and Evolution of an Exhibition
}

\author{
Chiara Ceci
}

Published online: 14 January 2009

(C) Springer Science + Business Media, LLC 2009

\begin{abstract}
Two hundred years after his birth, Darwin, originated by the American Museum of Natural History in New York, is the most important exhibition about the English scientist ever organized for the general public. This traveling exhibition has appeared in many versions worldwide, and a study of the relationships between local developers of the various editions of the exhibition underlines how a scientific exhibition and, more generally, science communication can succeed in striking a good equilibrium between universal content and cultural determinants.
\end{abstract}

Keywords Traveling exhibition · Darwin .

Cultural determinants

\section{Origin of the Exhibition}

Two hundred years after the birth of Charles Darwin, his theory of evolution is still at the center of cultural debates today, in part because of the speed with which the theory's scientific foundation is updated and in part because of its general philosophical implications regarding "man's place in nature." The Darwin exhibition is the most important exhibition about the English scientist ever organized for the general public, from scientists, to every child in his "bug period," to their parents and grandparents (Howe 2006). In keeping with the century-old tradition of the American Museum of Natural History of New York (AMNH), the exhibition approaches the facts and the theory of evolution

\section{Ceci $(\bowtie)$}

Department of Human Sciences for Education,

University of Milan Bicocca,

Milan, Italy

e-mail: chiara.ceci@unimib.it by natural selection from a historical perspective (Cohen 2006) as it combines history, narration, naturalism, the philosophy of science, and contemporary experimental research. The exhibition avoids caricatures (Dorit 2006) as it focuses on the adventurous biography of young Darwin: his complex family relationships, his immersion into English culture of the time (Levine 2007) and its conflicts, and his famous five-year voyage around the world. All these elements become evocative vehicles for recounting the birth of a revolutionary idea as the exhibition explores the early questions, the fascinating discoveries, the premonitions of an idea and its initial uncertainties, the fears, the long silence, and finally, the publication of his theory in 1859 .

Darwin is the first exhibition to feature an extensive and in-depth array of material related to Darwin's life and works. The exhibition is mounted in cooperation with English Heritage, the organization that administers Down House; the Natural History Museum, London; Cambridge University; and some of Darwin's living family members. The exhibition was curated by Niles Eldredge and designed and produced by the AMNH's Department of Exhibition in collaboration with the Museum of Science, Boston; The Field Museum, Chicago; the Royal Ontario Museum, Toronto, Canada; and the Natural History Museum, London, England. Unlike many traveling exhibitions that are organized by one museum and then purchased by others that become venues, in this case we see three of the host venues taking part in the organization of the exhibition to some extent. They were involved in the initial planning and were invited to join a series of organizing meetings in New York as the AMNH developed the exhibition.

The initial funding for the exhibition in New York came from private foundations. There were some problems with funding because the Museum failed to gain public funding, probably because the theme of the exhibition in today's 
USA might have seemed a bit politically uncomfortable to underwrite. So the entire cost of Darwin was covered by the participating museums, private donations, and profits from the visits, merchandising, and the sale of rights for other versions of the exhibition.

\section{An Exhibition Under Evolution: A Trip Around the World}

Darwin opened at the AMNH on November 19, 2005 and was initially planned to remain on view in New York until May 29, 2006, but the opening was extended to August 20, 2006 due to its great success (Adler 2005; Gitlin 2006; Vergano 2005; Williams 2005). The show moved to the Franklin Institute of Philadelphia (October 5, 2006December 31, 2006). Next, it went to the Museum of Science in Boston (February 18, 2007-April 27, 2007), then to the Field Museum in Chicago (June 15, 2007-January 1, 2008), on to the Royal Ontario Museum in Toronto (March 8, 2008-August 4, 2008), and after that to the Natural History Museum in London (November 14, 2008-April 19, 2009). The exhibition that traveled to all these museums was the very same one; adaptations to the new spaces were purely physical, and its curators did not change the exhibition's content beyond some minor adjustments and space reallocations. For example, in the venue of Chicago, the Field Museum's curator of anthropology proposed an alternative view regarding Homo floresiensis on the skull wall, and the Field Museum also added a part where four of its curators (a zoologist, botanist, anthropologist, and paleontologist) explained how evolution features in their work.

When the AMNH started to get many requests from museums and institutions around the world wishing to become venues for the exhibition, it became clear that a new strategy was needed for this exhibition. The AMNH started selling the intellectual property of the Darwin exhibition and providing the supply resources or physical reproduction of the contents and material when needed. The first new version to open was the Brazilian one, and since its first opening in São Paulo at the Museu de Arte (May 4, 2007-July 15, 2007), the exhibition has been to the Museu Histórico Nacional of Rio de Janeiro (January 23, 2008April 13, 2008; Wycoff 2008), Espaço do Complexo Cultural da República Norte in Brasilia (June 4, 2008-July 20, 2008), then to the Centro Cultural Oscar Niemeyer of Goiânia (August 19, 2008-October 5, 2008), then to the Sala de Eventos do Prédio da Pós-Graduação e Extensão of the Universidade Positivo in Curitiba (October 23, 2008November 30, 2008), and other future venues will cover most of the important cities in the country, including Belo Horizonte and Porto Alegre. Another edition of Darwin was hosted by the Auckland Museum (September 29, 2007-January 13, 2008), and the material of this edition after a new adaptation moved to Tokyo, at the National Museum of Nature and Science (March 18-June 22, 2008) and then to the second Japanese venue, the Osaka Museum of Natural History (July 19-September 21, 2008). The Portuguese edition of Darwin, A Evolução de Darwin, will open at the Museu Calouste Gulbenkian in Lisbon on February 13, 2009. The Italian edition will open in Rome at the Palazzo delle Esposizioni (February 12, 2009-May 3, 2009), and then it will move to Milan at the Rotonda della Besana.

All these versions share a basic structure with the original exhibition in New York, but each venue has some variations. First, there are physical differences due to the need of arranging the show in a different space (sometimes smaller, sometimes bigger). It is normal in a traveling exhibition to get the physical material and then mount it by adapting to new spaces, but in this case, there were many changes to be made. This is because the exhibition was designed around some objects that could not be in all those places at the same time and that were sometimes hard to substitute. Most of the time where you have to deal with documents and objects, you substitute facsimiles, but then the exhibition loses some of its magic. For this reason, all the venues tried to have some originals and in some cases rearranged the exhibition where they could not have them.

One constant issue was the question of live animals. Most of the places that hosted the exhibition were not used to live animals, and the spaces, costs, and care were important issues to solve in order to include them in the exhibition. Museums needed to be equipped to handle live animals for an extended period of time, and this was undertaken most of the time in collaboration with local zoos.

A main change - and one of the most interesting ones that can be traced in the various venues - is the insertion of a local context to Darwin, and every country tried to contextualize the exhibition. New sections were added to the exhibition in Brazil to talk about Darwin and his relationship with the country, about the "chaos of delight" the rainforest caused him, and also about his attitude toward slavery. In the Portuguese edition, a new part was added to address Darwin's stop at Cabo Verde, and the Italian edition features a section about Darwin's reception there that highlights correspondence he had with Italian scientists and academic institutions.

In the Italian edition, there will also be a completely new section on human evolution curated by Ian Tattersall. In the original version of the exhibition, human evolution occupied a very small part, but in Rome, due to the spaces that were available (almost $40 \%$ more than the original 
exhibition), it was possible to create an entire section dedicated to human evolution.

Some deeper changes were needed in some cases to orient the exhibition to the culture of the host country: In the Japanese version, for example, they had to add a new part at the beginning to explain how serious the religious aspects were for Darwin when he published the idea, because people could not understand why there was a conflict and why he had waited so long to go public with his ideas. On the same subject, on the other hand, in the London venue, they removed the video about scientists and faith, as they considered it unnecessary for their public. In Japan, they also added some videos where they show various kinds of animals Darwin saw in the voyage that we can still see at present. This was done in the interest of attracting a wider audience, which it was believed these videos might help with. Furthermore, they also added a small section named "Darwin and Japan," which explained how evolution theory had been accepted in Japan.

If we try to count the visitor numbers, we could say that Darwin has probably been the most successful scientific exhibition ever. We cannot determine a definite number, but we can use as indicators the data we have: In New York in just the first 3 months, they had nearly 200,000 visitors; the total number of visitors during the run of the exhibition in Chicago was 123,036; in a ten-week run in São Paulo, more than 175,000 visitors visited the exhibition, and 210,000 people visited the Tokyo venue in 88 days. Other numbers we may consider are those concerning the visitor targets of the still-open version and future ones: In London, this is 100,000 , the same in Lisboa, while in Italy, it is 200,000.

The exhibition was also a great media success both in the USA and abroad. All the major press covered the exhibitions: We can follow the success of Darwin from the cover of Newsweek for the opening in New York through all the major newspapers. In addition, there was quite good coverage in a number of scientific journals (Nature, Science, Lancet). The coverage in 2009 will probably be ever more intense, and also, the number of visitors in future versions could increase thanks to likely "Darwin year" effects.

It is also important to consider the didactic aspects of the exhibition because it is very popular among schools, and students of all ages are interested visitors. The AMNH developed an educational program for the exhibition that was then adopted by the other venues or used as inspiration for the subsequent versions. Of course, due to different educational standards worldwide and also to the fact that there were always slight variations in the exhibitions, none of the educational content of foreign editions was a mere translation of the original. In addition to organizing many activities and laboratory sessions, each venue coordinated many other events with the exhibition. All these complementary events have proved to be very popular, and the variety of activities coordinated with the exhibition was quite wide: from documentaries to lectures and panel discussions, to live performances, or to hands-on workshops; everything was designed to engage children, family, and all visitors and to make Darwin the centerpiece of other moments of discussion about the topic of the exhibition.

Those lucky enough to have the chance to travel the world and see all the versions of Darwin would have seen very similar exhibitions, with a recognizable structure, but every time they would have found some differences, some new material, a new section according to the country they were in, new educational material, and a different graphic for the external communication and website.

\section{Conclusions}

As we have seen, Darwin was born in New York at the AMNH in 2006 and has since been around the world both in other venues for the original exhibition and with new and different versions. It has been seen by hundreds of thousands of people in each venue and version, and if we sum all that up, it is probably one of the most successful exhibitions ever; surely it is a great success for a scientific one.

This research has analyzed the history and evolution of a unique and very interesting museological phenomenon. Looking at the many versions and venues of the exhibition and at the communicative instruments framing it (websites, educational outreach, events) and interviewing the curators of each edition, it was possible to trace the history of the exhibition worldwide and to analyze the communicative differences, which allowed the local cultural issues to emerge. We see how an exhibition travels around the globe maintaining its basic structure and a specific communicative mainstream, but we have pointed out that, in the process of its globalization, the exhibition develops local differences and, somehow, is always peculiar to each location.

The main observation that can be made is that every single venue has somehow personalized the exhibition (some more deeply than others), which was always due to physical constraints but also to cultural changes and local adaptations. It is also interesting to point out that in some countries, the exhibition was not organized by a natural history museum (Portugal, Brazil, and Italy) but by private foundations or companies. The location of the exhibitions then changed and in these countries was hosted by museums, palaces, and building usually used for art 
exhibitions or cultural events (in one of the Brazilian venues, it was mounted in space within a university).

The study of the relationships between local developers of the various editions of the exhibition points to how a scientific exhibition and, more generally, science communication can become a huge success, finding a good equilibrium between universal content and cultural determinants. Darwin is an exhibition that in every venue and edition shows local variations and adaptations. Charles Darwin would have loved this more than anybody.

Acknowledgments I thank all the people that have helped me in the research about the various editions of the exhibition and especially Thiago Carvalho, Yasunori Kawamura, Arlita McNamee, Grant Reid, Tom Skwerski, and Niles Eldredge.

\section{References}

Adler J. Evolution of a scientist. Newsweek 2005;146(22):50-8. November 28.

Cohen JE. The evolution of a great mind: the life and work of Darwin. Lancet 2006;367:721-2. 4 March.

Dorit R. Darwin on display. Am Sci 2006;94(2):178-80. Mar/ Apr.

Gitlin J. Darwin an exhibition at the American Museum of Natural History. J Clin Invest 2006;116(4):845.

Howe J. The origin of Darwin. Wired, Issue O3/06, 2006.

Levine G. The Darwin exhibition. Vic Lit Cult 2007;35:334-8.

Vergano D. The evolution of Darwin. USA Today, 06.11.2005, 2005.

Williams N. Evolution writ large. Curr Biol 2005;15(24):R973-4.

Wycoff M. Evolution from Darwin to DNA on show in Brazil. Evol Edu Outreach 2008;1(3):329-35. July. 